This document is confidential and is proprietary to the American Chemical Society and its authors. Do not copy or disclose without written permission. If you have received this item in error, notify the sender and delete all copies.

\title{
Identification of Novel 'Inks' for 3D Printing Using High Throughput Screening: Bioresorbable Photocurable Polymers for Controlled Drug Delivery
}

\begin{tabular}{|c|c|}
\hline Journal: & ACS Applied Materials \& Interfaces \\
\hline Manuscript ID & am-2017-15677w.R1 \\
\hline Manuscript Type: & Article \\
\hline Date Submitted by the Author: & 19-Dec-2017 \\
\hline Complete List of Authors: & $\begin{array}{l}\text { Louzao, Iria; Universidade de Santiago de Compostela, Organic Chemistry } \\
\text { Koch, Britta; The University of Nottingham, Laboratory of Biophysics and } \\
\text { Surface Analysis } \\
\text { Taresco, Vincenzo; University of Nottingham, Pharmacy } \\
\text { Ruiz Cantu, Laura; the university of nottingham, pharmacy } \\
\text { Irvine, Derek; University of Nottingham, School of Chemistry and School of } \\
\text { Chemical and Environmental Engineering } \\
\text { Roberts, Clive; The University of Nottingham, School of Pharmacy } \\
\text { Tuck, Christopher; University of Nottingham, Department of Mechanical, } \\
\text { Materials and Manufacturing Engineering } \\
\text { Alexander, Cameron; University of Nottingham, School of Pharmacy } \\
\text { Hague, Richard; The University of Nottingham, UK, Mechanical, Materials } \\
\text { and Manufacturing Engineering } \\
\text { Wildman, Ricky; University of Nottingham, Department of Chemical and } \\
\text { Environmental Engineering } \\
\text { Alexander, Morgan; The University of Nottingham, Laboratory of Biophysics } \\
\text { and Surface Analysis }\end{array}$ \\
\hline
\end{tabular}




\title{
Identification of Novel 'Inks' for 3D Printing Using
}

\author{
High Throughput Screening: Bioresorbable
}

\section{Photocurable Polymers for Controlled Drug}

\section{Delivery}

Iria Louzao, $\$ \S \dagger$ Britta Koch, $\$$ Vincenzo Taresco, $\$$ Laura Ruiz-Cantu, $\S$ Derek J. Irvine, $\S$ Clive J. Roberts, Christopher Tuck, § Cameron Alexander, $\$$ Richard Hague, $\S$ Ricky Wildman§ and Morgan R. Alexandert*

AUTHOR ADDRESS †School of Pharmacy and §Faculty of Engineering, University of Nottingham, Nottingham NG7 2RD (UK).

KEYWORDS: 3D printing, Drug Delivery, Polymer materials, Biomedical devices, Sustained drug release.

ABSTRACT A robust discovery methodology is presented to identify novel biomaterials suitable for 3D printing. Currently the application of Additive Manufacturing is limited by the availability of functional inks, especially in the area of biomaterials-this method tackles this problem for the first time allowing hundreds of formulations to be readily assessed. Several functional properties, including the release of an antidepressive drug (paroxetine), cytotoxicity and printability are screened for 253 new ink formulations in a high-throughput format as well as 
mechanical properties. The selected candidates with the desirable properties are successfully scaled up using 3D printing into a range of object architectures. A full drug release study, degradability and tensile modulus experiments are presented on a simple architecture to validating the suitability of this methodology to identify printable inks for $3 \mathrm{D}$ printing devices with bespoke properties.

\section{Introduction}

Additive Manufacturing, often termed 3D printing, is emerging as a technology with great potential for the manufacture of bespoke medical devices. Whilst there is some progress in identifying new materials for $3 \mathrm{D}$ printing, ${ }^{1-4}$ progress is slow and a limitation remains in the lack of functional materials that can currently be printed. ${ }^{5-10}$ To address this challenge, we propose a high throughput screening approach to identify "inks" for 3D printing of functional materials. We exemplify this by targeting the identification of polymers printable using UV photo initiation for optimal bioresorbable drug delivery devices. The approach involves high throughput screening of a library of materials deposited as small polymer spots arranged as micro arrays, which are then used to identify which of the materials have the appropriate mechanical and cell compatibility properties. This surface-focused micro array screening approach is complemented by assessing larger samples in well-plates for bulk performance determination, which in this exemplification of the approach was quantification of drug release. From these high-throughput screening of different properties, 19 materials were shortlisted. A final selection was made based on an estimate of the printability, which led to the identification of materials that could be scaled up for $3 \mathrm{D}$ printing. Hit materials from the library were then used to fabricate drug-containing 
objects suitable for subcutaneous implantation. ${ }^{11}$ Release profiles from these objects were quantified by standard drug dissolution testing procedures, illustrating the success of this approach in identifying new inks ready for use in the manufacture of bioresorbable medical devices by $3 \mathrm{D}$ printing. ${ }^{12}$ To the best of our knowledge, this is the first high throughput screening approach described for identifying inks for 3D printing or bioresobable drug delivery polymers. The method illustrated here offers opportunities in many other fields where new functional 3D printable materials are required.

The main advantage of additive manufacturing with respect to traditional manufacturing techniques is the freedom of object design, providing an ideal opportunity for manufacturing personalized medicines ${ }^{13}$ and devices. ${ }^{14,15}$ Of the $3 \mathrm{D}$ printing technologies available, jetting of liquid inks to form solid materials ${ }^{16}$ enabled by piezoelectric inkjet methods allows for superior resolution ${ }^{17,18}$ when compared to other popular techniques such as extrusion (often used for bioprinting/cell printing). ${ }^{19-21}$ However, the range and functionality of materials available for inkjet printing are limited and a major barrier to the adoption of new materials is the printability requirements of a particular ink formulation, which needs to meet physical and rheological constraints in order to be ejectable from a nozzle..$^{22,23}$

Herein we explore a library of copolymers based on acrylated oligo or poly ( $\beta$-amino ester) ${ }^{24-26}$ photo curable macromers (abbreviated to PBAE) and acrylic monomers, to identify suitable photocurable 3D printable ink formulations with a range of drug release properties. These bioresorbable materials based on acrylated $\beta$-amino esters (Figure 1a) are oligomeric (macromer) products from a Michael addition reaction and have enormous potential in applications where the 
polymer is required to hydrolytically degrade in service, such as during or after drug delivery from an implant. To illustrate this, we have chosen paroxetine hydrochloride (Figure 1c), an antidepressant drug in a group of medicines called selective serotonin reuptake inhibitors. To overcome side effects related to treatments with paroxetine, such as cardiac arrhythmia or insomnia, extended release from a subcutaneous implant is a desirable strategy to reduce these serious side effects possible from oral systemic delivery over long periods of time. ${ }^{27,28}$ For our illustration of a high throughput screening study this drug has the advantage that it is auto fluorescent allowing us to use fluorescence spectrophotometry to quantify the drug released, but the 384 well plate format allows for the analysis of any compound using auto sampling methods and quantification by high performance liquid chromatography mass spectrometry. By examining drug release from well plated for up to 2 months in vitro, in addition to high throughput analysis of cytotoxicity and modulus, we selected candidate materials for scale-up to 3D printing which were further refined by consideration of the printability of the inks. Objects suitable for subcutaneous implantation were successfully printed into a variety of forms with the selected ink and subjected to macroscopic tensile mechanical testing, drug release and polymer degradation studies.

\section{Results and Discussion}

\section{Polymer library synthesis and micro array fabrication}

PBAEs are easily synthesized in bulk by a Michael addition reaction of primary amines (or a bis(secondary) amine) with diacrylates following the approach of Anderson et al. ${ }^{24}$ (Figure 1ab). The diacrylates were used in excess in order to preserve acrylate functionalities at both ends. A 
total of 6 diacrylates $(A-F$, Figure 1a) and 6 amines (1-6, Figure 1a) were combined at $1.2: 1$ diacrylate/amine molar ratio to give rise to 36 macromers in principle, identified as diacrylateamine (letter-number) code according to Figure 1a (Table S1, Supporting Information). To further explore the effect of composition, the diacrylate/amine ratio was also modified to 1.2:1, 1.5:1 and 2:1 in one case (identified as $C 3, C 3-15$ and $C 3-2$ respectively). Diacrylate $C$ was further combined with another three amines 7-9 to form a total of 42 macromers.

a) Diacrylates<smiles>C=CC(=O)OCCC(C)OC(=O)C=C</smiles>

B<smiles>C=CC(=O)OCCCCC(=O)OCC</smiles><smiles></smiles><smiles>C=CC(=O)OCCOCCOC(=O)C=C</smiles><smiles>C=CC(=O)OCC(C)(C)OCC(C)(C)OC(=O)C=CF</smiles>

b) General structure of macromers<smiles>[R][R](C)OC(=O)CCN([R3])CCC(=O)OC(C)=[R](C)OC(=O)C=C</smiles>

\section{Methacrylamide}<smiles>C=C(C)C(=O)Nc1ccc(O)cc1</smiles><smiles>COCCN</smiles>

$3 \mathrm{H}_{2} \mathrm{~N}$<smiles>NCCO</smiles><smiles>CCC(N)O</smiles><smiles>NC(CO)CO</smiles><smiles>[3H]OCCN1CCOCC1</smiles>

8<smiles>CNCCNC</smiles>

c)<smiles>COc1ccc(OCOc2ccc(F)cc2)cc1OC[C@H]1CNCCC1c1ccc(Cl)cc1</smiles> 
Figure 1. (a) Chemical structures of the diacrylates $(A-F)$ and amines (1-9) used to synthesise the PBAE macromers and methacrylamide G. (b) General structure of PBAE macromers. (c) Chemical structure of paroxetine hydrochloride.

While piezoelectric 3D printing is highly sensitive to ink viscosity, this is not the case with pin-printing where grooved reservoirs in metal pins are filled by capillary forces on immersion into liquid inks. This technique allows for microarray preparation of a very wide range of inks which we printed prior to high throughput characterization of the UV cured spots in the accessible form of a polymer micro array. ${ }^{29-34}$ Pure PBAE are in general too viscous for piezoelectric ink jet printing. The microarray strategy allows for the rapid screening of a large amount of materials by combining PBAE and diacrylate monomers $(A-F)$.

Combinatorial mixtures of 42 PBAEs and 6 diacrylates and one acrylamide (mixed with both PBAE and diacrylates, Figure 1a) gave rise to 253 materials. To prepare the library as both micro arrays on glass slides and in well-plates, PBAE and monomer $G$ were mixed with diacrylates A$\mathrm{F}\left(1: 1 \mathrm{w} / \mathrm{w}\right.$ ratio). The solvent $\left(\mathrm{DMF}, \mathrm{bp}=153^{\circ} \mathrm{C}\right)$ and any eventual unreacted volatile monomer (i.e. $E, \mathrm{bp}=162^{\circ} \mathrm{C}$ ) were removed after polymerization in a vacuum oven as indicated by surface chemical characterization techniques (ToF-SIMS, Supporting Information). The co-polymers are identified as diacrylate $(A-G)$ with PBAE (from $A 1$ to $F \sigma$ ), resulting in copolymers denoted in this form, $A A 1$ to GF6.

\section{High throughput micro array assessment}

The polymer microarrays were used to carry out high throughput cytotoxicity assessment, mechanical property measurements using atomic force microscopy (AFM) and surface chemical characterization (Figure 2) by ToF-SIMS (Supporting Information, Figures S15). ${ }^{30,29}$ High throughput measurement of the elastic modulus was achieved using automated AFM analysis of 
the array (Figure 2b) by PeakForce quantitative nanomechanics (QNM) imaging mode, revealing a wide range of elastic moduli throughout had been achieved on the polymer library.

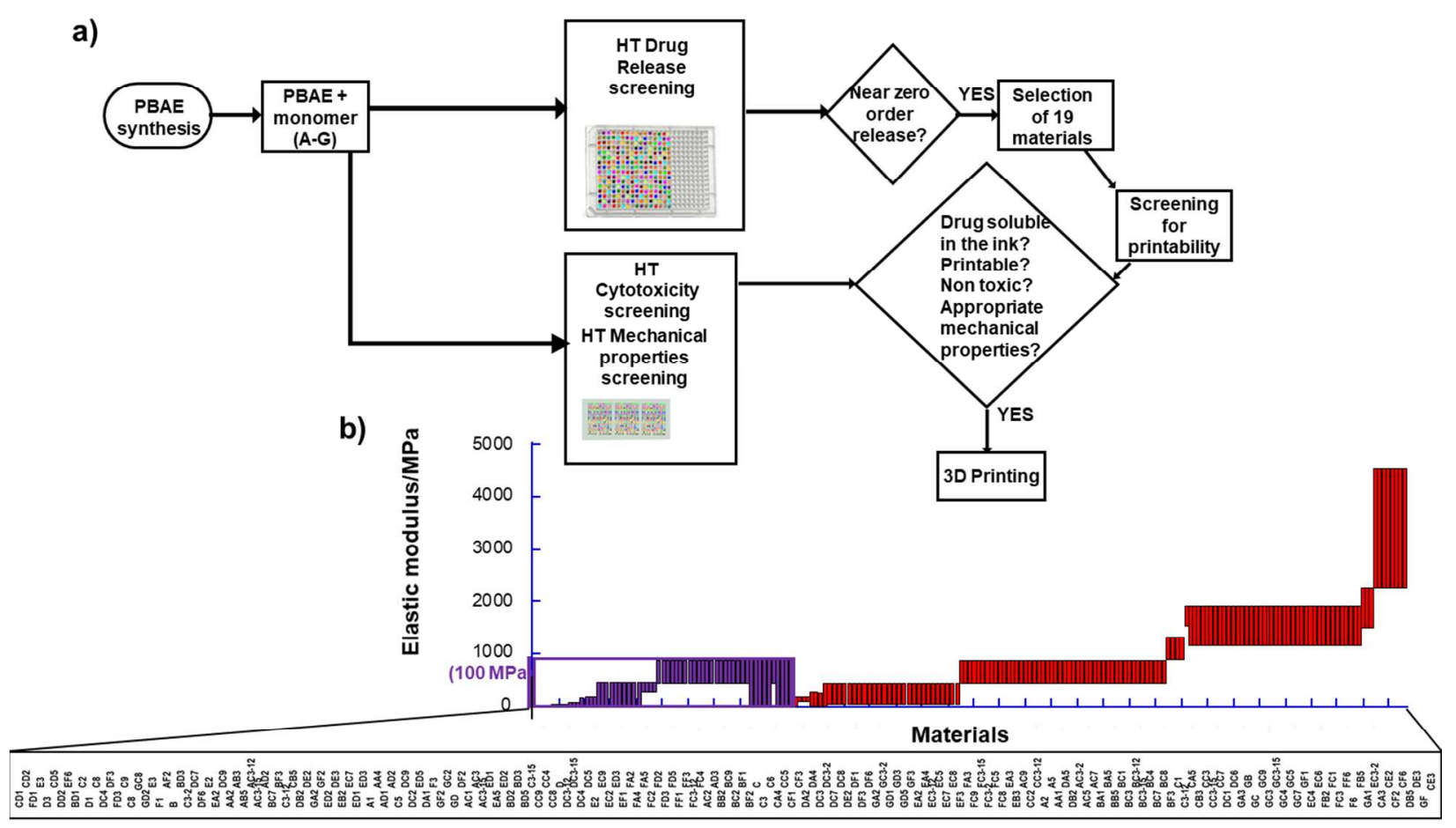

Figure 2. (a) Schematic workflow depicting the high-throughput methodologies applied and material selection at the different steps. (b) Elastic moduli represented as interval values in MPa ranked from lower (left) to upper values. For clarity, the values represented in purple (up to 100 $\mathrm{MPa}$ ) are plotted on an expanded scale.

In the novel high throughput polymer micro array cytotoxicity assay, dye penetration and cell number quantification indicated a slight reduction in mesenchymal stem cell viability after 48 hours of culture for all polymer spots (Supporting Information, Figure 3b and Figure S8). This is consistent with a previous report noting such an effect ascribed to degradation products of PBAE,${ }^{35}$ although the cell survival and viability was still high compared to the cytotoxic effect induced by a cyanoacrylate as a comparator (Figure $3 \mathrm{~b}$ and Figure S8). For the PBAE library 
under investigation, no component showed a specifically detrimental effect so all material chemistries went forward for further consideration.

Polymer mechanical properties are relevant to biomaterial application, and consequently we have developed a high throughput method to determine stiffness modulus from the micro array format and provide choice of material further downstream. ${ }^{36-40}$ AFM has previously been used in a high-throughput to morphologically characterize polymer micro arrays but not previously to determine modulus. ${ }^{34}$ PeakForce QNM, which allows simultaneous imaging and mechanical property measurement was used to automatically analyze all the spots on the microarray. The information acquired provides the Derjaguin-Muller-Toporov (DMT) modulus ${ }^{41,42}$ amongst other sample properties. Cantilevers suitable for the measurement of moduli between 5 and 2000 MPa were used to obtain quantitative measurements across most of the polymers (see Supporting Information for details). ${ }^{42-45}$ Due to the uncertainty of the geometrical models used to represent the probe tips, it is most appropriate to present these data as ranges of elastic moduli instead of discrete values (Figure 2b). Moduli were measured ranging from $1 \mathrm{MPa}$ to $5 \mathrm{GPa}$. To put these moduli in context, medical polyurethanes fall in the range of 5-7 MPa, PDMS ranges from 48 $\mathrm{kPa}$ up to $2 \mathrm{MPa}^{46}$ mixtures of PDMS and polyurethane are used measuring a few (15-35) $\mathrm{MPa}^{47}$ subcutaneous tissue around $4 \mathrm{kPa},{ }^{48}$ dermis $2.8-4 \mathrm{MPa}^{49}$ and human bone is found in the range of 3-20 GPa. ${ }^{50}$ Flexible and intermediate modulus materials with a stiffness in the MPa range are thought to be most suitable for subcutaneous implantation to achieve a balance of mechanical stability and flexibility. ${ }^{47}$ The range of material moduli achieved in this library of bioresorbable materials offers a route to tuning the material to the desired function.

\section{Library fabrication in well plates for drug release quantification}


Ready determination of drug release requires separate compartments into which the eluted drug can be collected and quantified in solution. Consequently, the library was photocured in a 384 well-plate format, where each well contained a solution of the drug and the photo initiator [2\% in DMF, 2,2-dimethoxy-2-phenylacetophenone (DMPA)] added to the diacrylate-PBAE mixtures in $70 \%$ DMF (w/v), so as to achieve $100 \mathrm{ng}$ of drug per well. The drug loading was chosen such that the release concentration was within limits required in the body. ${ }^{51,52}$ After UV curing and vacuum drying, the samples were incubated in $100 \mu \mathrm{L}$ phosphate buffered saline (PBS, $\mathrm{pH}$ 7.4). At selection times, $75 \mu \mathrm{L}$ of the dissolution media was transferred to black polystyrene plates for fluorescence measurements $\left(\lambda_{\mathrm{ex}}=270, \lambda_{\mathrm{em}}=335\right)$ by using an automatic pipetting robot (Biotek). The experiments were performed in triplicate and included a control plate containing the (co)polymers without drug as a background. The release profiles for the materials are presented in Figure 3a for times up to 2 months. These reveal a wide range of release rates from the polymers: for ease of visual interpretation, only the $20 \mathrm{~h}$ and 2 month time points of release are shown from the $1 \mathrm{~h}$ time point measurements made up to 2 months (Figures S1-S6). 
a)

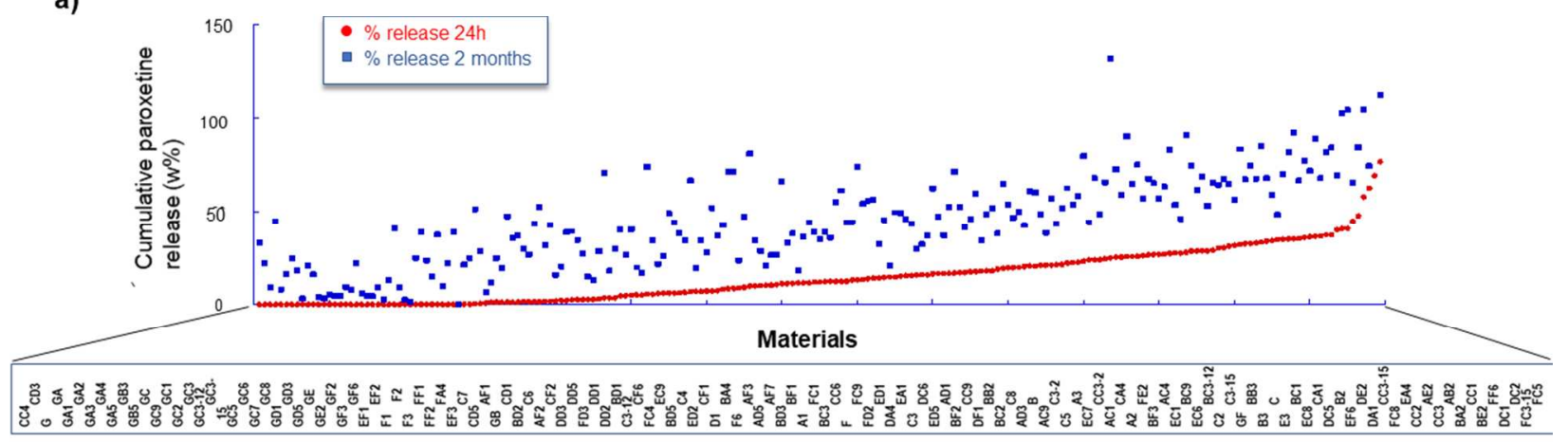

b)

$$
\text { ङ }
$$

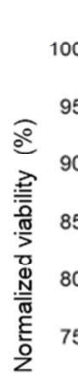

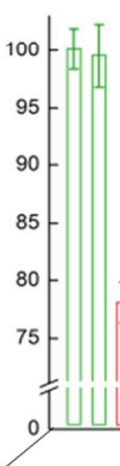

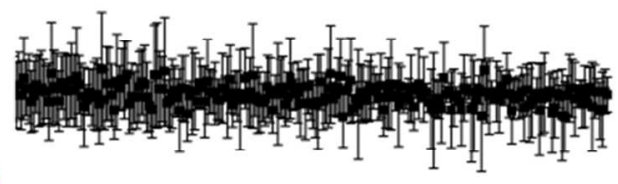

c)

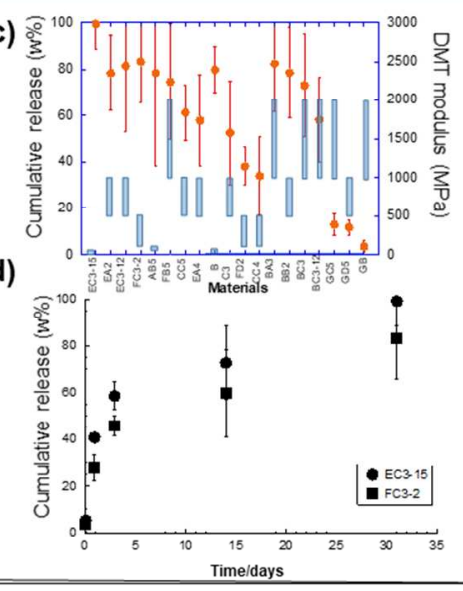

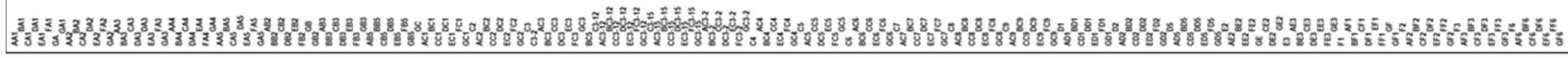

Figure 3. (a) Cumulative paroxetine release for the materials ordered from lower (left) to higher (right) cumulative release at 20h (red). Release after 2 months (64 days) is depicted in blue. (b) Normalized cell viability quantified from the Neutral Red stain for the PBAE materials. Green bars show negative controls (left to right: bare glass and pHEMA-coated glass), the red bar the positive control (cyanoacrylate adhesive). (c) Release profile after one month (31 days, orange dots) and AFM determined elastic modulus intervals (blue bars) for 19 materials. (d) Cumulative kinetic release profile for 2 of the hit materials, over 31 days. All error bars depict standard deviation from the mean. 
A number of materials, desirable for extended release in that they follow a near zero-order ${ }^{53,54}$ release profile were identified (Figure 3). Nineteen polymers were selected as of interest based on linear release profile. All of them also showed an initial burst release (Figure 3 and Figure S7) commonly observed in commercial formulations of drugs from polymer drug delivery matrices $^{53,11}$ including polyurethane (PU), ${ }^{55}$ polydimethylsiloxane (PDMS) ${ }^{56,57}$ or poly(ethylene vinyl acetate), ${ }^{58}$ PLGA and methacrylate based materials. ${ }^{53}$ This is beneficial in some situations, in the case of paroxetine, an initial amount in blood might be desirable to reach a therapeutic level rapidly.

\section{Printability screening}

In order to test printability in a piezo electric system, a number of aspects of the ink formulations needed to be considered. Firstly, the 19 candidate materials showing near zero order release were reduced to 9 combinations based on the solubility of the PBAE in the diacrylate monomer without any additional solvent-for maximum simplicity, resulting in the use of only PBAE materials based on $\mathrm{C}$ and A. The resulting 9 combinations were then screened using the criteria of ejection from an automated piezo electric microarray printer (SciFlexarrayer S5, Scenion). This has similarities with inkjet 3D printers, but with the advantage of being able to simultaneously screen multiple inks utilising just $50 \mu \mathrm{l}$ of each from a well plate in a fully automated manner. Although the high viscosity of our formulations does not allow for a highthroughput printability screening by using system, it may be applied to low viscosity formulations in high-throughput format. Solvent dilution was used as a surrogate for increased temperature to reduce viscosity in the $3 \mathrm{D}$ printer. The inks were prepared at $6.25 \%, 12.5 \%, 25 \%$ and $50 \%$ in DMF (w/v) and $50 \mu \mathrm{l}$ of each solution was transferred into 384 well plate (See 
Supporting Information for details). Although all the inks could be aspirated and ejected under almost all levels of dilution, the drug was readily soluble in only the most hydrophilic monomers $(D-F)$. From the 4 inks that dissolve the drug, only FC3-2 and EC3-15 could be ejected as drops at the minimum dilution and thus at the lowest temperature (Table 1 and Figure S9). Interestingly, these formulations involve both the $C 3$ PBAE (tripropylene glycol combined with triethylamine at different ratios) copolymerized with polyethylene glycol (MW=500) and diethylene glycol ( $F$ and $E$, Figure 1) respectively. Several PBAE prepared from tripropylene glycol appear to be miscible with several diacrylates giving formulations suitable to be printed. These were therefore assessed to be the formulations most likely ready to be printed by using the original screened formulation without further adjustments for viscosity (i.e. increasing diacrylate/PBAE ratio). The elastic modulus of these was also within the MPa range (Figure 3c), suitable to prepare drug delivery subcutaneous implants. ${ }^{47}$ This method was able to predict the two formulations ultimately found to be printable, indicating its suitability for rapid assessment of candidate materials for 3D printing. 
Table 1. Printability screening results $(A=$ aspirated and $E=$ ejected $)$ for the 9 inks prepared at $25 \%$ and $50 \%$ in DMF (w/v).

\begin{tabular}{|c|c|c|c|c|}
\hline \multirow{2}{*}{$\begin{array}{l}\operatorname{Ink}(\%)^{\lfloor\mathrm{a}]} \\
\operatorname{Ink}\end{array}$} & \multicolumn{2}{|c|}{$25 \%$} & \multicolumn{2}{|c|}{$50 \%$} \\
\hline & $\mathrm{A}$ & $E$ & $\mathrm{~A}$ & $E$ \\
\hline $\boldsymbol{B A 3}$ & $x$ & $x$ & $x$ & $x$ \\
\hline BC3 & $\boldsymbol{V}$ & $\mathbf{v}$ & $x$ & $\mathbf{x}$ \\
\hline$C 3$ & $\boldsymbol{v}$ & $\mathbf{v}$ & $x$ & $x$ \\
\hline$C C 4$ & $\mathbf{V}$ & $\mathbf{V}$ & $x$ & $\mathbf{x}$ \\
\hline CC5 & $\boldsymbol{v}$ & $\mathbf{v}$ & $x$ & $x$ \\
\hline$E A 2$ & $\mathbf{v}$ & $\mathbf{x}$ & $x$ & $\mathbf{x}$ \\
\hline FC3-2 & $\mathbf{v}$ & $\mathbf{v}$ & $\boldsymbol{v}$ & $\boldsymbol{V}$ \\
\hline EC3-12 & $\mathbf{v}$ & $\mathbf{v}$ & $x$ & $x$ \\
\hline EC3-15 & $\boldsymbol{V}$ & $\mathbf{v}$ & $\sqrt{ }$ & $x$ \\
\hline
\end{tabular}

\section{Scale up of hit polymers using UV photo initiated inkjet printing}

As a consequence of the screening protocols, the two formulations identified (FC3-2 and EC315) were shown to produce materials with a near-zero order release profile (Figure 3cd) and were suitable for 3D printing (Table 1). Additionally, they proved to be non-toxic to cells (Figure $2 \mathrm{~b}$ and S8) and the modulus was within the range of commonly utilized biomedical elastomers (Figure 3c) ${ }^{47,11}$. Both the measured viscosity and the surface tension of the ink formulations selected for scale up were in the appropriate range for printability, both with and without drug at a temperature of $60^{\circ} \mathrm{C}$, i.e. between $10-13 \mathrm{cP}$, with the range of $9-15 \mathrm{cP}$ recognized as optimal ${ }^{22}$ (Table 2 and Figure S12). The two candidate materials were found to be dispensable on a commercial inkjet printer (Dimatix DMP 2800) by using standard waveforms (suitable to print 
commercial UV curable inks) where single spherical drops without satellites were achievable just through the adjustment of the cartridge working temperature (between 25 and $70^{\circ} \mathrm{C}$ in all cases). In order to test the predictability of our printability screening, an ink predicted to not be printable from the high throughput test ( $B A 3$ in Table 1) was checked for dispensing, and was found not to be printable on the Dimatix DMP 2800 by using standard waveforms at the highest temperature available $\left(70{ }^{\circ} \mathrm{C}\right)$, giving us confidence that our method is able to discriminate between inks that can and can't be used for 3D printing. Scale up was demonstrated by successfully printing different objects from both inks (Figure 4c-h) on polyethylene terephthalate (PET) foil using 6 of the available 16 nozzles simultaneously, with curing initiated through concurrent illumination of UV during each pass of the print head. Simple objects of various geometries were produced including squares, rectangles, grids and a honeycomb using the number of layers to control thickness between 0.1 to $0.6 \mathrm{~mm}$; control of architecture is a powerful route to control release. ${ }^{59}$

Table 2. Viscosity at printing temperatures and surface tension measured both with and without drug incorporated paroxetine in the ink formulation.

\begin{tabular}{|c|c|c|}
\hline & FC3-2 & $E C 3-15$ \\
\hline Viscosity [MPa.s] ${ }^{\lfloor\mathrm{a}]}$ & $13.18 \pm 0.36$ & $10.61 \pm 0.10$ \\
\hline $\begin{array}{l}\text { Surface tension } \\
{\left[\mathrm{mN} \cdot \mathrm{m}^{-1}\right]^{[\mathrm{b}]}}\end{array}$ & $32.81 \pm 0.21$ & $31.96 \pm 0.11$ \\
\hline $\begin{array}{l}\text { Surface tension } \\
{\left[\mathrm{mN} \cdot \mathrm{m}^{-1}\right]^{[\mathrm{c}]}}\end{array}$ & $33.11 \pm 0.23$ & $32.75 \pm 0.38$ \\
\hline
\end{tabular}

A full object characterization involving drug release, polymer degradability and mechanical characterization for the FC3-2 material was achieved by printing cm sized squares (25 layers, 
Drug release and degradability experiments were performed with 5 replicates of $1 \mathrm{~cm}^{2}$ printed squares of FC3-2 (25 layers) by immersing the printed materials in PBS to such a volume that upon elution of all drug the concentration reached would be $10 \mu \mathrm{g} / \mathrm{mL}$, and incubated at $37^{\circ} \mathrm{C}$ (Figure 4b). The thin film geometry was selected as a simple starting point from which shape can be adjusted in the future for fine-tuning of drug release according to personalized requirements. The linear behavior and burst effect is maintained when scaling-up, which illustrates the success and suitability of the screening methodology proposed.

The current demonstration system is suitable for commencing in vitro studies to assess the actual effect of geometry in vivo and in preclinical animal models.

For a future local implant, those devices show the potential to maintain a therapeutically local drug concentration over at least three months. Hydrolytic degradation experiments with analogous samples without incorporating the drug were performed (Figure S14). The mass loss recorded on an initially weekly, then bi-weekly basis showed a degradation of the polymer 
slower than the drug release. This is consistent with polymer degradation not being the only mechanism of release, but rather diffusion of the active from the polymer plays a major role as observed for commercially biodegradable polymers. ${ }^{60}$

a)

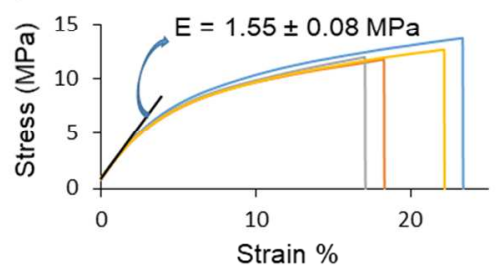

b)

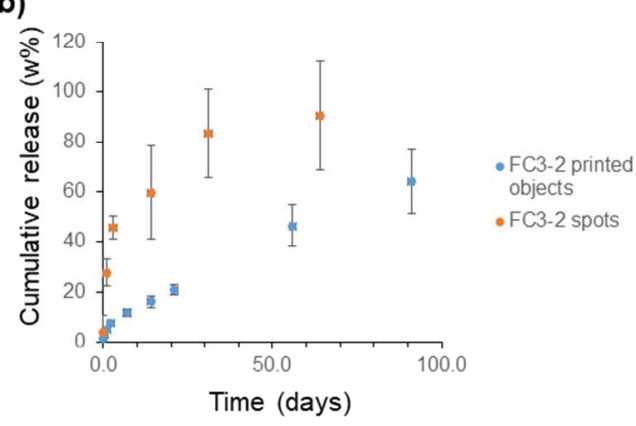

c)

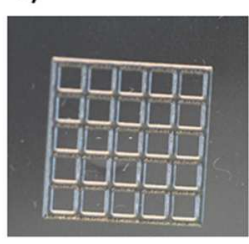

f)

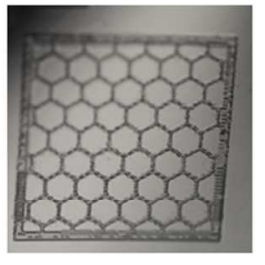

d)

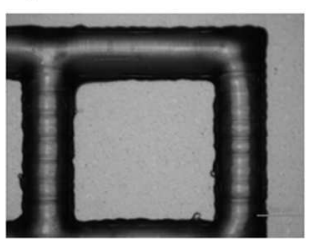

g)

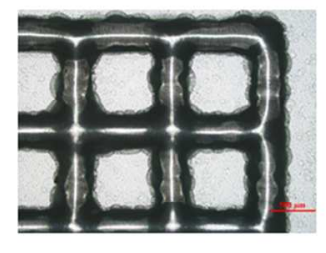

e)

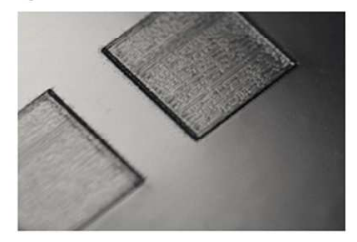

h)

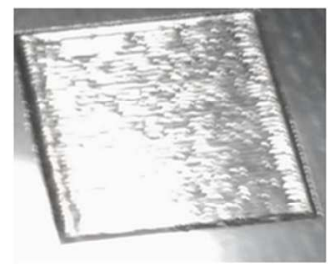

Figure 4. (a) Results of tensile experiments (4 replicates) representing stress (MPa) vs. percentage of strain. The slope of the linear part is the elastic Young modulus (E). (b) Comparison of the cumulative paroxetine release profile of $F C 3-2$ printed $1 \mathrm{~cm}^{2}$ squares (25 layers, 5 replicates, blue) and HT screening in well plates (orange, 3 replicates. Note that the release should be completed at day 42, prior to the last measurement). (c- h) Exemplary pictures (c, e, f, h) and micrographs (d,g) of printed structures: (c) FC3-2 grid, 99 and (d) 50 layers, (e) FC3-2 1x1 cm 25-layer squares, (f) 1x1 cm 5-layer honeycomb (g) EC3-15 grid, 20 layers and (h) EC3-15 25-layer 1x1 cm square. 


\section{Conclusions}

In summary, we have developed the first high-throughput screening methodology to identify 3D printable inks, exemplified here using UV curable bioresorbable co-polymers with drug release properties relevant to releasing implants; near zero order release profile compatible with drug concentration close to therapeutic levels. The 3D printability of hit materials was assessed to identify inks for scale up to objects that exhibited extended and linear drug release profiles achieving therapeutic concentrations and appropriate elastic modulus for biomedical devices. The UV initiated inkjet printing approach was used to achieve different object geometries illustrating the flexibility of form that can be achieved. High throughput cytotoxicity experiments were developed based on polymer micro arrays on which high throughput elastic modulus measurements were also undertaken for the first time. This information was complemented by applying ToF SIMS as high throughput surface chemical characterisation method. The methodology described herein is proposed as a robust tool to identify novel printable functional materials which we see being of great utility to the emergence of $3 \mathrm{D}$ printing in biomedicine and may readily be combined with other high-throughput material screening methods in the biomaterials field such as cell attachment, bacterial resistance and immune modulation.

\section{ASSOCIATED CONTENT}

Supporting Information. Experimental details regarding poly- $\beta$-amino ester (PBAE) synthesis, microarray preparation, screening for drug release kinetics, atomic force microscopy, screening for PBAE-array cytotoxicity, screening for printability, 3D printing, rheology and surface tension measurements, drug release of printed materials, degradability experiments by 
dissolution, Time of Flight-Secondary Ion Mass Spectrometry (ToF-SIMS), Gel Permeation

Chromatography (GPC) and Nuclear Magnetic Resonance (NMR) spectra are supplied as

Supporting Information (PDF). The following files are available free of charge.

\section{AUTHOR INFORMATION}

\section{Corresponding Author}

*E-mail: morgan.alexander@nottingham.ac.uk

\section{Present Addresses}

$†$ Centro Singular de Investigación en Química Biolóxica e Materiais Moleculares (CIQUS) and Departamento de Química Orgánica, Universidade de Santiago de Compostela, Jenaro de la Fuente s/n, Santiago de Compostela, 15782 (Spain)

\section{Author Contributions}

The manuscript was written through contributions of all authors. Iria Louzao carried out the bulk of the experimental work and manuscript preparation for this paper with additional experiments carried out by Britta Koch, Vincenzo Taresco, Laura Ruiz-Cantu. The work was conceived, organised and made possible with funding won by Clive J. Roberts, Christopher Tuck, Ricky Wildman, Cameron Alexander, Richard Hague and Morgan R. Alexander. Manuscript drafting and submission was led by Richard Hague, Cameron Alexander, Ricky Wildman and Morgan R. Alexander. All authors have given approval to the final version of the manuscript.

\section{Funding Sources}

This work was funded by the EPSRC grants Multifunctional Additive Manufacturing (EP/K005138/1), EPSRC Centre for Innovative Manufacturing in Additive Manufacturing 
(EP/I033335/2), Programme Grant for Next Generation Biomaterials Discovery (EP/N006615/1) and Formulation for 3D printing: Creating a plug and play platform for a disruptive UK industry (EP/N024818/1).

\title{
Notes
}

The authors declare no competing financial interests.

\section{ACKNOWLEDGMENT}

Daniel G. Anderson (Massachusetts Institute of Technology) is acknowledged for his suggestion of using PBAEs as a bioresorbable polymeric library. The authors thank Dr. Xinyong Chen, Dr. Gemma Bray, Dr. David Scurr, Dr. Andrew Hook, Dr. Belen Begines, Annesi Giacaman and Dr. Ehab Saleh (University of Nottingham) for providing Excel macros to analyse AFM data, the gift of JCRB1149 human mesenchymal stem cells, their kind assistance with ToFSIMS and Biodot dispensing system, providing waveforms for 3D printing, acquiring tensile strength data and kind assistance for acquiring some pictures of printed objects respectively.

\author{
ABBREVIATIONS \\ AFM atomic force microscopy, DMF dimethylformamide, DMPA 2,2-dimethyl-2- \\ phenylacetophenone, DMT Derjaguin-Muller-Toporov, PBAE poly- $\beta$-amino esters, PBS \\ phosphate buffered saline, pHEMA poly-hydroxyethylmethacrylate, PLGA poly-lactic-co- \\ glycolic acid, QNM quantitative nanomechanics, ToF-SIMS Time-of-flight secondary ions mass \\ spectrometry.
}

\section{REFERENCES}

(1) He, Y.; Tuck, C. J.; Prina, E.; Kilsby, S.; Christie, S. D. R.; Edmondson, S.; Hague, R. J. M.; Rose, F. R. A. J.; Wildman, R. D. A New Photocrosslinkable Polycaprolactone-Based 
Ink for Three-Dimensional Inkjet Printing. J. Biomed. Mater. Res. - Part B Appl. Biomater. 2017, 105 (6), 1645-1657.

(2) Hart, L. R.; Li, S.; Sturgess, C.; Wildman, R.; Jones, J. R.; Hayes, W. 3D Printing of Biocompatible Supramolecular Polymers and Their Composites. ACS Appl. Mater. Interfaces 2016, 8 (5), 3115-3122.

(3) Chia, H. N.; Wu, B. M. Recent Advances in 3D Printing of Biomaterials. J. Biol. Eng. 2015, $9(1), 4$.

(4) He, Y.; Wildman, R. D.; Tuck, C. J.; Christie, S. D. R.; Edmondson, S. An Investigation of the Behavior of Solvent Based Polycaprolactone Ink for Material Jetting. Sci. Rep. 2016, 6, 20852.

(5) Guvendiren, M.; Molde, J.; Soares, R. M. D.; Kohn, J. Designing Biomaterials for 3D Printing. ACS Biomater. Sci. Eng. 2016, 2 (10), 1679-1693.

(6) Jose, R. R.; Rodriguez, M. J.; Dixon, T. A.; Omenetto, F.; Kaplan, D. L. Evolution of Bioinks and Additive Manufacturing Technologies for 3D Bioprinting. ACS Biomater. Sci. Eng. 2016, 2 (10), 1662-1678.

(7) Nadgorny, M.; Xiao, Z.; Connal, L. A. 2D and 3D-Printing of Self-Healing Gels: Design and Extrusion of Self-Rolling Objects. Mol. Syst. Des. Eng. 2017, 2 (3), 283-292.

(8) Nadgorny, M.; Xiao, Z.; Chen, C.; Connal, L. A. Three-Dimensional Printing of pHResponsive and Functional Polymers on an Affordable Desktop Printer. ACS Appl. Mater. Interfaces 2016, 8 (42), 28946-28954.

(9) Bakarich, S. E.; Gorkin, R.; Panhuis, M. in het; Spinks, G. M. 4D Printing with 
Mechanically Robust, Thermally Actuating Hydrogels. Macromol. Rapid Commun. 2015, $36(12), 1211-1217$.

(10) Peterson, G. I.; Larsen, M. B.; Ganter, M. A.; Storti, D. W.; Boydston, A. J. 3D-Printed Mechanochromic Materials. ACS Appl. Mater. Interfaces 2015, 7 (1), 577-583.

(11) Anselmo, A. C.; Mitragotri, S. An Overview of Clinical and Commercial Impact of Drug Delivery Systems. J. Control. Release 2014, 190, 15-28.

(12) Kempin, W.; Franz, C.; Koster, L.-C.; Schneider, F.; Bogdahn, M.; Weitschies, W.; Seidlitz, A. Assessment of Different Polymers and Drug Loads for Fused Deposition Modeling of Drug Loaded Implants. Eur. J. Pharm. Biopharm. 2017, 115 (Supplement C), 84-93.

(13) Khaled, S. A.; Burley, J. C.; Alexander, M. R.; Yang, J.; Roberts, C. J. 3D Printing of Five-in-One Dose Combination Polypill with Defined Immediate and Sustained Release Profiles. J. Control. Release 2015, 217, 308-314.

(14) Hutmacher, D. W. Scaffolds in Tissue Engineering Bone and Cartilage. Biomaterials 2000, 21 (24), 2529-2543.

(15) Gross, B. C.; Erkal, J. L.; Lockwood, S. Y.; Chen, C.; Spence, D. M. Evaluation of 3D Printing and Its Potential Impact on Biotechnology and the Chemical Sciences. Anal. Chem. 2014, 86 (7), 3240-3253.

ASTM International. Standard Terminology for Additive Manufacturing -General Principles-Terminology; 2015.

(17) Spears, B. R.; Marin, M. A.; Chaker, A. N.; Lampley, M. W.; Harth, E. Precise 
Microscale Polymeric Networks through Piezoelectronic Inkjet Printing. ACS Biomater. Sci. Eng. 2016, 2 (8), 1265-1272.

(18) Tao, H.; Marelli, B.; Yang, M.; An, B.; Onses, M. S.; Rogers, J. A.; Kaplan, D. L.; Omenetto, F. G. Inkjet Printing of Regenerated Silk Fibroin: From Printable Forms to Printable Functions. Adv. Mater. 2015, 27 (29), 4273-4279.

(19) Kolesky, D. B.; Truby, R. L.; Gladman, A. S.; Busbee, T. A.; Homan, K. A.; Lewis, J. A. 3D Bioprinting of Vascularized, Heterogeneous Cell-Laden Tissue Constructs. Adv. Mater. 2014, 26 (19), 3124-3130.

(20) Sydney Gladman, A.; Matsumoto, E. A.; Nuzzo, R. G.; Mahadevan, L.; Lewis, J. A. Biomimetic 4D Printing. Nat Mater 2016, 15 (4), 413-418.

(21) Kolesky, D. B.; Homan, K. A.; Skylar-Scott, M. A.; Lewis, J. A. Three-Dimensional Bioprinting of Thick Vascularized Tissues. Proc. Natl. Acad. Sci. 2016, 113 (12), 31793184.

(22) Derby, B. Inkjet Printing of Functional and Structural Materials: Fluid Property Requirements, Feature Stability, and Resolution. Annu. Rev. Mater. Res. 2010, 40 (1), $395-414$.

(23) de Gans, B.-J.; Duineveld, P. C.; Schubert, U. S. Inkjet Printing of Polymers: State of the Art and Future Developments. Adv. Mater. 2004, 16 (3), 203-213.

(24) Anderson, D. G.; Tweedie, C. A.; Hossain, N.; Navarro, S. M.; Brey, D. M.; Van Vliet, K. J.; Langer, R.; Burdick, J. A. A Combinatorial Library of Photocrosslinkable and Degradable Materials. Adv. Mater. 2006, 18 (19), 2614-2618. 
(25) Green, J. J.; Zugates, G. T.; Tedford, N. C.; Huang, Y.-H.; Griffith, L. G.; Lauffenburger, D. A.; Sawicki, J. A.; Langer, R.; Anderson, D. G. Combinatorial Modification of Degradable Polymers Enables Transfection of Human Cells Comparable to Adenovirus. Adv. Mater. 2007, 19 (19), 2836-2842.

(26) Green, J. J.; Chiu, E.; Leshchiner, E. S.; Shi, J.; Langer, R.; Anderson, and D. G. Electrostatic Ligand Coatings of Nanoparticles Enable Ligand-Specific Gene Delivery to Human Primary Cells. Nano Lett. 2007, 7 (4), 874-879.

(27) Group, D. U. A. Paroxetine: A Selective Serotonin Reuptake Inhibitor Showing Better Tolerance, but Weaker Antidepressant Effect than Clomipramine in a Controlled Multicenter Study. J. Affect. Disord. 1990, 18 (4), 289-299.

(28) Grimsley, S. R.; Jann, M. W. Paroxetine, Sertraline, and Fluvoxamine: New Selective Serotonin Reuptake Inhibitors. Clin. Pharm. 1992, 11 (11), 930-957.

(29) Urquhart, A. J.; Anderson, D. G.; Taylor, M.; Alexander, M. R.; Langer, R.; Davies, M. C. High Throughput Surface Characterisation of a Combinatorial Material Library. Adv. Mater. 2007, 19 (18), 2486-2491.

(30) Algahtani, M. S.; Scurr, D. J.; Hook, A. L.; Anderson, D. G.; Langer, R. S.; Burley, J. C.; Alexander, M. R.; Davies, M. C. High Throughput Screening for Biomaterials Discovery. J. Control. Release 2014, 190, 115-126.

(31) Celiz, A. D.; Smith, J. G. W.; Langer, R.; Anderson, D. G.; Winkler, D. A.; Barrett, D. A.; Davies, M. C.; Young, L. E.; Denning, C.; Alexander, M. R. Materials for Stem Cell Factories of the Future. Nat Mater 2014, 13 (6), 570-579. 
(32) Celiz, A. D.; Smith, J. G. W.; Patel, A. K.; Hook, A. L.; Rajamohan, D.; George, V. T.; Flatt, L.; Patel, M. J.; Epa, V. C.; Singh, T.; Langer, R.; Anderson, D. G.; Allen, N. D.; Hay, D. C.; Winkler, D. A.; Barrett, D. A.; Davies, M. C.; Young, L. E.; Denning, C.; Alexander, M. R. Discovery of a Novel Polymer for Human Pluripotent Stem Cell Expansion and Multilineage Differentiation. Adv. Mater. 2015, 27 (27), 4006-4012.

(33) Hammad, M.; Rao, W.; Smith, J. G. W.; Anderson, D. G.; Langer, R.; Young, L. E.; Barrett, D. A.; Davies, M. C.; Denning, C.; Alexander, M. R. Identification of Polymer Surface Adsorbed Proteins Implicated in Pluripotent Human Embryonic Stem Cell Expansion. Biomater. Sci. 2016, 4 (9), 1381-1391.

(34) Hook, A. L.; Yang, J.; Chen, X.; Roberts, C. J.; Mei, Y.; Anderson, D. G.; Langer, R.; Alexander, M. R.; Davies, M. C. Polymers with Hydro-Responsive Topography Identified Using High Throughput AFM of an Acrylate Microarray. Soft Matter 2011, 7 (16), $7194-$ 7197.

(35) Hawkins, A. M.; Milbrandt, T. A.; Puleo, D. A.; Hilt, J. Z. Synthesis and Analysis of Degradation, Mechanical and Toxicity Properties of Poly( $\beta$-Amino Ester) Degradable Hydrogels. Acta Biomater. 2011, 7 (5), 1956-1964.

(36) Dean, M. N.; Swanson, B. O.; Summers, A. P. Biomaterials: Properties, Variation and Evolution. Integr. Comp. Biol. 2009, 49 (1), 15-20.

(37) Reilly, G. C.; Engler, A. J. Intrinsic Extracellular Matrix Properties Regulate Stem Cell Differentiation. J. Biomech. 2010, 43 (1), 55-62.

(38) Nair, L. S.; Laurencin, C. T. Biodegradable Polymers as Biomaterials. Prog. Polym. Sci. 
2007, 32 (8-9), 762-798.

(39) Mohanty, A. K.; Misra, M.; Hinrichsen, G. Biofibres, Biodegradable Polymers and Biocomposites: An Overview. Macromol. Mater. Eng. 2000, 276-277 (1), 1-24.

(40) Jain, R. A. The Manufacturing Techniques of Various Drug Loaded Biodegradable Poly(lactide-Co-Glycolide) (PLGA) Devices. Biomaterials 2000, 21 (23), 2475-2490.

(41) Derjaguin, B. V; Muller, V. M.; Toporov, Y. U. P. Effect of Contact Deformations on the Adhesion of Particles. J Colloid Interface Sci 1975, 53 (2), 314-326.

(42) Dokukin, M. E.; Sokolov, I. Quantitative Mapping of the Elastic Modulus of Soft Materials with HarmoniX and Peak Force QNM AFM Modes. Langmuir 2012, 28 (46), $16060-16071$.

(43) Dokukin, M. E.; Sokolov, I. On the Measurements of Rigidity Modulus of Soft Materials in Nanoindentation Experiments at Small Depth. Macromolecules 2012, 45 (10), $4277-$ 4288.

(44) Clifford, C. A.; Seah, M. P. Quantification Issues in the Identification of Nanoscale Regions of Homopolymers Using Modulus Measurement via AFM Nanoindentation. Appl. Surf. Sci. 2005, 252 (5), 1915-1933.

(45) Jee, A.-Y.; Lee, M. Comparative Analysis on the Nanoindentation of Polymers Using Atomic Force Microscopy. Polym. Test. 2010, 29 (1), 95-99.

(46) Brown, X. Q.; Ookawa, K.; Wong, J. Y. Evaluation of Polydimethylsiloxane Scaffolds with Physiologically-Relevant Elastic Moduli: Interplay of Substrate Mechanics and Surface Chemistry Effects on Vascular Smooth Muscle Cell Response. Biomaterials 2005, 
$26(16), 3123-3129$.

(47) Simmons, A.; Padsalgikar, A. D.; Ferris, L. M.; Poole-Warren, L. A. Biostability and Biological Performance of a PDMS-Based Polyurethane for Controlled Drug Release. Biomaterials 2008, 29 (20), 2987-2995.

(48) Iatridis, J. C.; Wu, J.; Yandow, J. A.; Langevin, H. M. Subcutaneous Tissue Mechanical Behavior Is Linear and Viscoelastic under Uniaxial Tension. Connect. Tissue Res. 2003, 44 (5), 208-217.

(49) Zahouani, H.; Pailler-Mattei, C.; Sohm, B.; Vargiolu, R.; Cenizo, V.; Debret, R. Characterization of the Mechanical Properties of a Dermal Equivalent Compared with Human Skin in Vivo by Indentation and Static Friction Tests. Ski. Res. Technol. 2009, 15 (1), 68-76.

(50) Staiger, M. P.; Pietak, A. M.; Huadmai, J.; Dias, G. Magnesium and Its Alloys as Orthopedic Biomaterials: A Review. Biomaterials 2006, 27 (9), 1728-1734.

(51) Bourin, M.; Chue, P.; Guillon, Y. Paroxetine: A Review. CNS Drug Rev. 2001, 7 (1), 2547.

(52) Tasker, T. C. G.; Bye, C. M.; Zussman, B. D.; Link, C. G. G. Paroxetine Plasma Levels: Lack of Correlation with Efficacy or Adverse Events. Acta Psychiatr. Scand. 1989, 80 (S350), 152-155.

(53) Huang, X.; Brazel, C. S. On the Importance and Mechanisms of Burst Release in MatrixControlled Drug Delivery Systems. J. Control. Release 2001, 73 (2-3), 121-136.

(54) Fu, Y.; Kao, W. J. Drug Release Kinetics and Transport Mechanisms of Non-Degradable 
and Degradable Polymeric Delivery Systems. Expert Opin. Drug Deliv. 2010, 7 (4), 429444.

(55) Kang, E.; Vedantham, K.; Long, X.; Dadara, M.; Kwon, I.-K.; Sturek, M.; Park, K. DrugEluting Stent for Delivery of Signal Pathway-Specific 1,3-Dipropyl-8-Cyclopentyl Xanthine. Mol. Pharm. 2009, 6 (4), 1110-1117.

(56) Woolfson, A. D.; Malcolm, R. K.; Morrow, R. J.; Toner, C. F.; McCullagh, S. D. Intravaginal Ring Delivery of the Reverse Transcriptase Inhibitor $\{\mathrm{TMC}\} 120$ as an \{HIV\} Microbicide. Int. J. Pharm. 2006, 325 (1-2), 82-89.

(57) Malcolm, R. K.; Woolfson, A. D.; Toner, C. F.; Morrow, R. J.; McCullagh, S. D. LongTerm, Controlled Release of the HIV Microbicide TMC120 from Silicone Elastomer Vaginal Rings. J. Antimicrob. Chemother. 2005, 56 (5), 954-956.

(58) Arnold, R. R.; Wei, H. H.; Simmons, E.; Tallury, P.; Barrow, D. A.; Kalachandra, S. Antimicrobial Activity and Local Release Characteristics of Chlorhexidine Diacetate Loaded within the Dental Copolymer Matrix, Ethylene Vinyl Acetate. J. Biomed. Mater. Res. Part B Appl. Biomater. 2008, 86B (2), 506-513.

(59) Kyobula, M.; Adedeji, A.; Alexander, M. R.; Saleh, E.; Wildman, R.; Ashcroft, I.; Gellert, P. R.; Roberts, C. J. 3D Inkjet Printing of Tablets Exploiting Bespoke Complex Geometries for Controlled and Tuneable Drug Release. J. Control. Release 2017, 261, $207-215$.

(60) Lao, L. L.; Venkatraman, S. S.; Peppas, N. A. Modeling of Drug Release from Biodegradable Polymer Blends. Eur. J. Pharm. Biopharm. 2008, 70 (3), 796-803. 


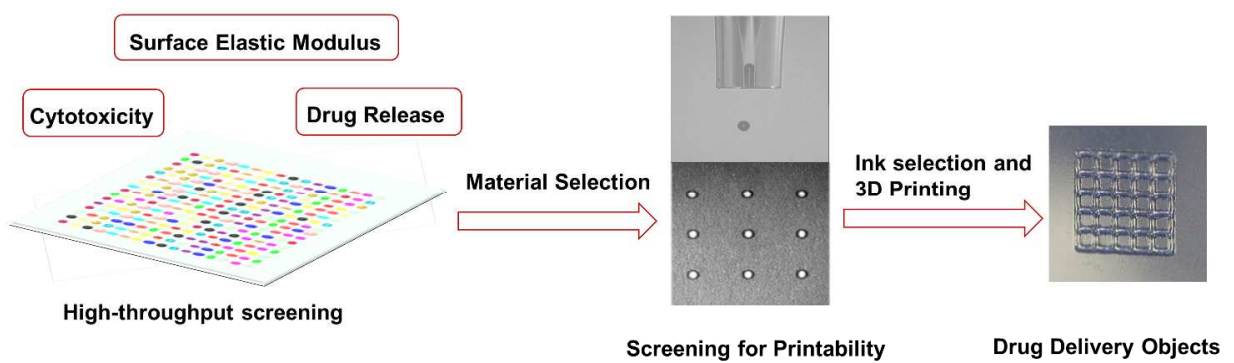

TOC

$840 \times 360 \mathrm{~mm}(96 \times 96 \mathrm{DPI})$ 